\title{
A private hospital management system
}

\section{Dr. M. H. B. Ariyaratne}

Postgraduate Institute of Medicine, University of Colombo, Sri Lanka.

E-mail address: buddhika.ari@gmail.com

eHealth Sri Lanka 2010,1(suppl.1):S16

DOI: http://dx.doi.org/10.4038/sljbmi.v1i0.3551

Only the Abstract is available

\begin{abstract}
In Sri Lanka, several private hospitals have adapted computerised systems for management purposes. This is a description of such systems used in a major private hospital in Southern Province to manage admissions and day care surgeries. Virtually no emphasis was given on recording clinical data of patients. The admissions are recorded at the reception real-time and all the units are updated. The issue of medicines, performing procedures and delivery of other services are all recorded. The admission fee, room charges, nursing charges, linen charges, medicine charges, professional charges are all automatically calculated. If done manually, the accurate calculation would have been difficult as some charges are done only once for the admission, some are for the duration of the stay, while others depend on time spend in different rooms or ITU. At any given moment, the current bill is ready, and if the patient is discharged, he does not have to wait for hours till the bill is finalised manually. The system can handle cash payments, credit payments and payments that are covered by insurance companies. These different payment methods have different charges for the same service, and system looks after the difficult part of calculations. The day-end summaries, shift-end summaries, professional payment summaries are useful to handle daily income. Payments by Insurance Agencies, their balance and credit limit are also efficiently handled.
\end{abstract}

Keywords - clinical data of patients, different payment methods 